\title{
Technology Transfer to The Students of Elementary and Junior High Schools
}

\author{
Takaharu KURODA, Kisarazu National College of Technology, Kisarazu, Chiba, Japan
}

\author{
Key words: Elementary and junior high school, Collaboration, Educational support
}

\begin{abstract}
In Japan, population of 15 years old or younger has been decreasing and interest in science has also been falling. Therefore, a decrease in applicant magnification to technical colleges and lack of scholastic ability become a problem. In addition, a growing demand for regional alliances in higher education institutes from 1990s.

In some technical colleges, an education support business to an elementary and junior high school has already been carried out and it became the good motivation for making handmade things.

Our college has been interacting with neighbor elementary and junior high schools, and in 2002, established Cooperative Technology Center to promote local interchange and the education support, that cooperated with a local social organization, for elementary and junior high school students. This report introduces the practical examples such support our college has been providing.
\end{abstract}

\section{Introduction}

Global lack of energy, and increasing demand for environmental safeguard raised an issue to high educational institutions to educate engineers to be more creative. However, the population of fifteen years old and younger is decreasing, and the interest toward science is falling. These facts caused problems of a decreasing number of the applicant magnification to technical colleges, and lack of scholastic ability. In addition to these problems, since 1990s, higher level of regional alliances has been demanded to high educational institutes.

In 2002, new guidelines for elementary and junior high schools were carried out, and introduced five-day school week and composite learning class. The new guidelines relaxed the intensity of education that resulted in a decreased time on science. As a result, there has not been enough time to spend especially on experiments and observation, which are crucial to deepen the understanding on science. Furthermore, a number of experienced teachers are also falling, and to aggravate the problem, the preparation time for class and the training time for teachers are not enough because of other school affairs. An international research [1] shows that big proportion of students of elementary and junior high schools' think, "science class is not interesting." or "I think learning science will not help me in my daily life." It is clear and understood that so-called "science detached room" and "making of thing detached rooms" increased.

Under this circumstance, some technical colleges have already provided a support business to elementary and junior high schools and achieved positive results. [2][3][4]

Our college has been interacting with neighbor elementary and junior high schools, and in 2002, established Cooperative Technology Center to promote local interchange and the education support, that cooperated with a local social organization, for elementary and junior high school students. This report introduces the practical examples such support our college has been providing.

\section{Actions in Kisarazu national college}

Kisarazu national college of technology has been promoting open lectures to the public since 1987. These lectures share the technical knowledge of our schoolteachers, targeting mainly citizen and students. In addition, our school provides "experience entrance" for junior high school students to experience the content of our school programs, and "fun science" for elementary school students to share fun experience using science surrounded us. These social interactions and services are promoted mainly through the Cooperative Technology Center, which was established in 2000. The Cooperative Technology Center's main activities are, to assist a joint research and development and to provide social contribution such as educational support business for elementary and junior high school students. This report introduces two of the educational support business for elementary and junior high school students- (1) Delivery lesson, and (2) Telework seminar (Station square college). 


\section{Delivery lesson}

Since 1996, science teachers, as a core member, have been visiting junior high schools to deliver a lesson focusing on "making things". Table 1 shows the schedule of delivery lessons in 2006. The lessons were held twelve times among six junior high schools near-by. With Daiichi junior high, we have tightened the relationship as "School support volunteer (science class)" since 2003. This activity was adopted in a science partnership program of Ministry of Education, Culture, Sports, Science and Technology in 2005.

This section introduces some of the delivery class's contents. As an educational support for junior high school science class, the themes of the class are, light, wind, sound, electricity, and chemical change. The purpose is to understand the link between science technology and our life. We try to get students' interest and attention on science technology by using familiar events as examples, and let students experience making things. Figure. 1 is a picture of making kaleidoscope. This class was titled "World of light" and student can experience demonstration experiments, and production of a kaleidoscope in $100 \mathrm{~min}$. Figure.2 is a picture of students experimenting the performance of "Wind cars" they made. Figure. 3 shows the "Making of germanium radio" using paper glass as a capacitor. Figure.4 is a wiring diagram of optical transmitter combined with LED: Light emitting diode, and PT: Phototransistor. Figure.5 further shows the production example of the optical communication. This optical communication teaching material can be bought by mail order via the Internet.

According to a research on 276 first year junior high school students, $76 \%$ like making things such as science contraction, but only $50 \%$ wonder about the mechanism of machineries surrounding them. This is thought to be due to the technology advancement and technicality have made that people not worry about the systems and principles. Table 2 shows the survey results taken after the delivery lesson. Roughly, $93 \%$ of the student enjoyed the class, and about $64 \%$ of the students were now interested in science technology. In addition, 92\% of the students

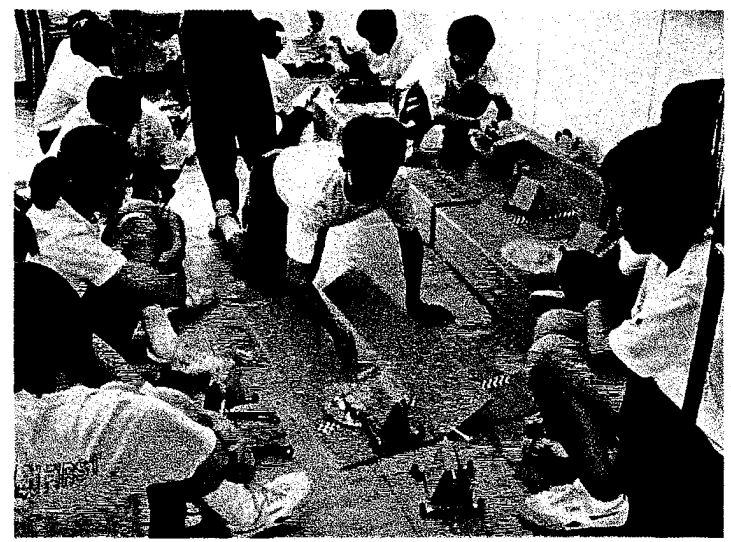

Fig.2 Experiments of "wind car"

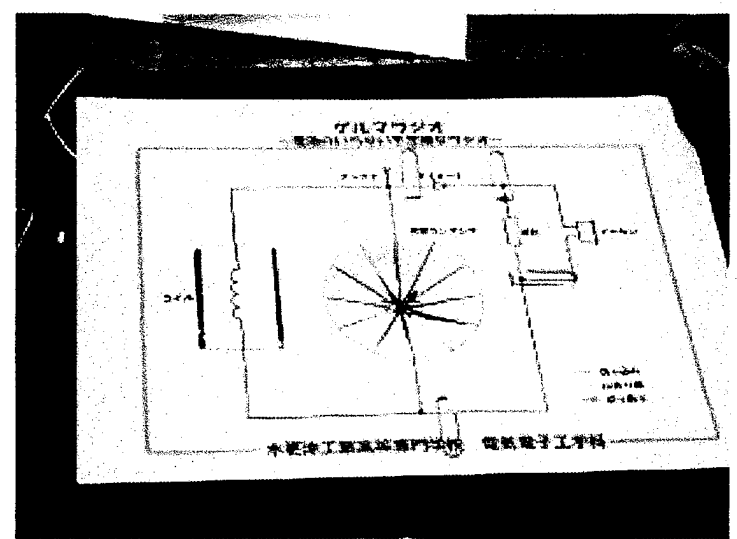

Fig.3 Making of germanium radio 
participated in the next delivery lesson. From these results, we know that students have high interest on technical lectures, systems, and principles. Students who were not motivated by the lesson were the ones who could not successfully make the teaching materials. Therefore, it is clear that success is linked with student's motivation and interest.

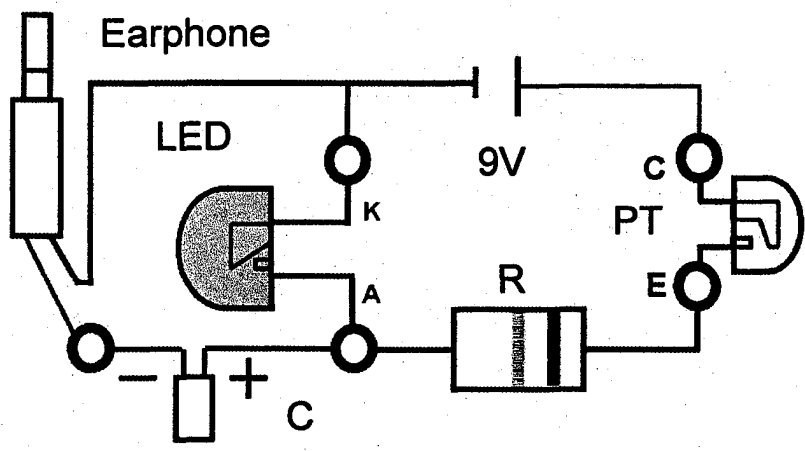

Fig.4 Constitution of transmitter

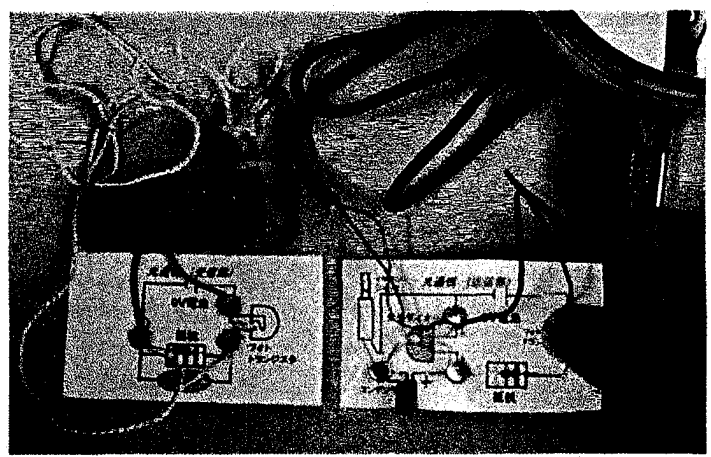

Fig.5 Transmission test from a transmitter to a receiver

Following problems are found;

(1) Time and cost: In order to keep the students' concentration, the class should be within $100 \mathrm{~min}$ from the introduction to the completion of teaching material experiments. Delivery lessons are held on weekdays, thus there is an obstacle against securing enough technical college students as TA (teaching assistants). Furthermore, we need to adjust how to cover the cost.

(2) Correspond to students' individual variation (Ability and interest): There is an individual variation on production time and interest, which lead to uneven completion and satisfaction. Therefore, the support by TA is necessary, and additional support after school for students who want to continue the work is required.

(3) Coexisting the production experience and academic interest: We found that it is important to teach students the pleasure of completing a project. Considerations to make every student complete projects on time, especially students who are not good at using scissors or a cutter knife need attention. Making a production manual is an effective method to cut down the production time. However, there are also negative effect of the students becoming too worried about details on the manual and forget about thinking of the roles of each material. In the future, development of a program including failure experience, which is crucial to science technology advancement, and a program that leads to academic interests.

Table 2 Questionnaire results after lessons

\begin{tabular}{|c|c|c|c|c|c|}
\hline Questons & Excellent & Good & Average & Bad & Failing \\
\hline Interested in lessons (\%) & 70 & 23 & 6 & 0 & 1 \\
\hline $\begin{array}{c}\text { Interested in technology } \\
\text { and science (\%) }\end{array}$ & 31 & 33 & 24 & 7 & 5 \\
\hline $\begin{array}{c}\text { Do you want to participate } \\
\text { on the next time? (\%) }\end{array}$ & 75 & 16 & 7 & 0 & 2 \\
\hline
\end{tabular}

\section{Telework seminar (Station square college)}

We started this business so that public- from children to seniors- can have a chance to participate in lectures and enjoy science. We work as one of the lifetime educational business in Kisarazu-shi telework seminar. Precisely, we have been operating it as Station square college seminar in Ainsu Building since 2001. Table 3 shows the list of the seminars in 2006. Figure 6 is 
public information magazine of Kisarazu-shi about the seminar. There are varieties of contents from IT, Robots to making simple things, targeting from businessmen to children. Citizens can easily experience science technology, and roughly 100 participants come every year. Various activity of telework center of Kisarazu-shi was evaluated such as President prize from Japan Telework Association and a child science education program of association of Japan Television Workshop of Sony education foundation.

Table 3 Station square college schedule in 2006

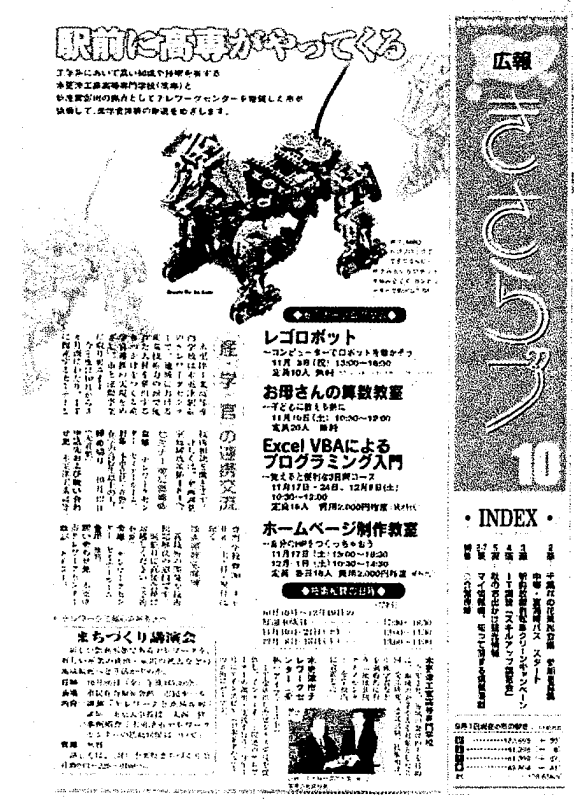

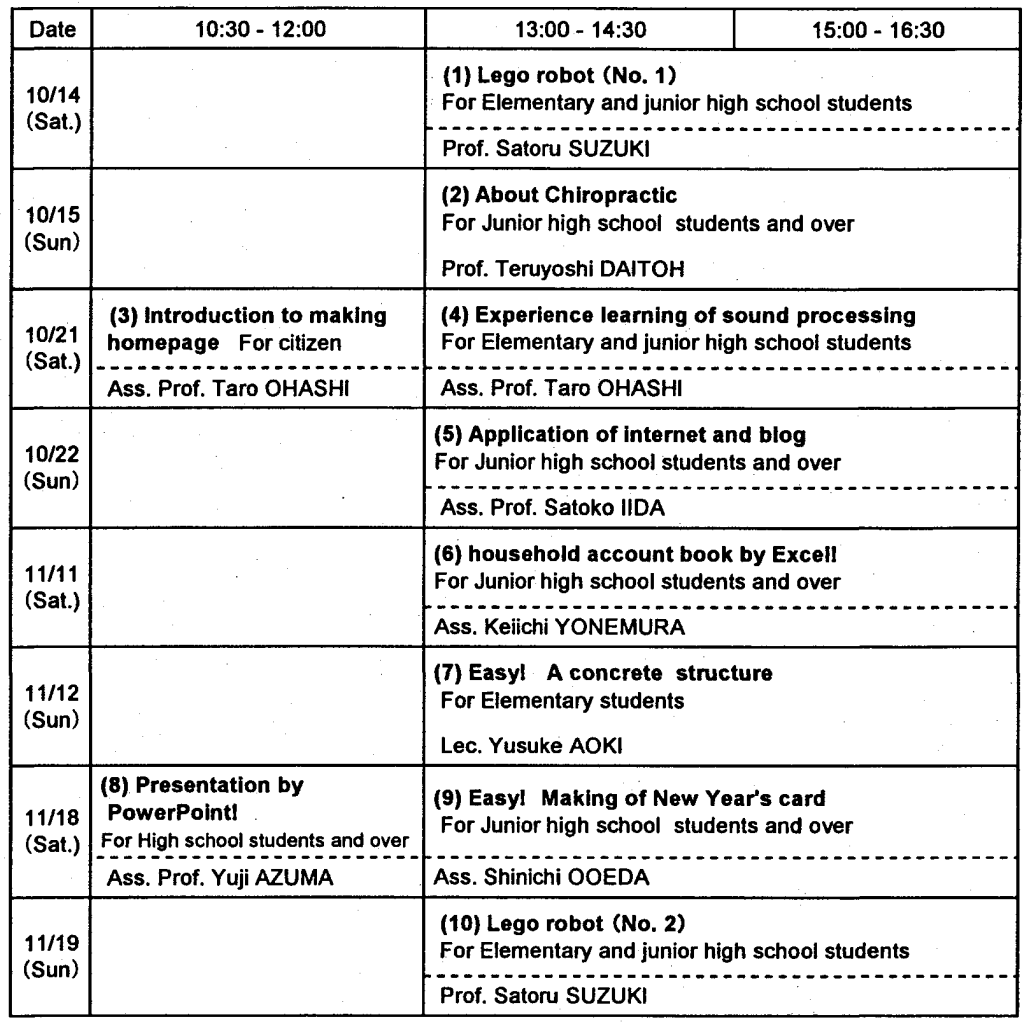

\section{Conclusion}

This report introduced the delivery lessons and Telework seminar (Station square college), but we also actively participating in other science technology promotion business by having partnership with a museum and the local municipality.

We want to continue motivating students to know the pleasure of making things, and interest in machineries' systems and principles via the delivery lessons etc. Furthermore, because our teaching staff is limited, we would like to hold lectures for teachers of elementary and junior high schools' to promote education of science technology. At the same time, we would like to raise creative and high natured engineers by encouraging PBL: Project Based learning or Problem Based Learning such as participating in instructor volunteer activities or teaching material development.

\section{References}

[1] "Trends in International Mathematics and Science Study 2003", International Association for the Evaluation of Educational Achievement (IEA), 2004.

[2] Hiroshi OHSAWA et.al., "A Collaboration with Science Teacher in Ongoing Guest Teachers Program to Junior High Schools", Journal of Education in the Colleges of Technology, No.28, pp.821-825, 2005

[3] Jun KYOKANE et.al., "Modern GP and PBL education of advance engineering course students", Technical College Education Conference 2006, pp.1-4, 2006

[4] Akihiro MINAMI et.al., "A possible Approach to the Prevention of dislikable to handmade craft for Students of Elementary and Junior High School", Journal of Education in the Colleges of Technology, No.27, pp.787-792, 2004 